\title{
Partial characterization and cloning of the genome of PvSNPV (= BP-type virus) pathogenic for Penaeus vannamei
}

\author{
Jean-Robert Bonami ${ }^{1, *}$, Linda D. Bruce ${ }^{2}$, Bonnie T. Poulos ${ }^{2}$, Jocelyne Mari ${ }^{2}$, \\ Donald V. Lightner ${ }^{2}$
}

\author{
${ }^{1}$ Laboratoire de Pathologie Comparée, URA 1184, Université Montpellier II, Sciences et Techniques du Languedoc, \\ Place Eugène Bataillon, F-34090 Montpellier Cedex 5, France \\ ${ }^{2}$ Department of Veterinary Science, University of Arizona, Tucson, Arizona 85721, USA
}

\begin{abstract}
PVSNPV isolated from the shrimp Penaeus vannamei was characterized after purification. In negative staining, the rod-shaped, enveloped particles were 312 to $320 \mathrm{~nm}$ in length and 75 to $87 \mathrm{~nm}$ in diameter. The nucleocapsids, 306 to $312 \mathrm{~nm}$ in length and 62 to $68 \mathrm{~nm}$ in diameter, showed a crosshatched surface arranged in a helical pattern and a trilaminar structure capping both extremities. Purified occlusion body subunits (polyhedrin subunits) were 17 to $19 \mathrm{~nm}$ in diameter and, in SDS-PAGE, demonstrated 1 major polypeptide of $52 \mathrm{kDa}$. BamHI digested viral genome revealed at least 7 different fragments. Cloning of these DNA fragments, and the resulting study of them, revealed the presence of 2 more fragments which had co-migrated in gel electrophoresis. The cloned fragments, which represent about $40 \%$ of the estimated size of the genome, were characterized by their size and by the position of restriction sites. When the cloned fragments were labeled and used as probes, no homology was found among the different inserts. These gene probes reacted with different BP-type strains, but not with uninfected shrimp tissue. The gene probes also did not react with shrimp tissues infected with other shrimp viruses, indicating their specificity for the BP-type viruses.
\end{abstract}

KEY WORDS: BP · PvSNPV · Penaeid shrimp - Genome cloning $\cdot$ Gene probes

\section{INTRODUCTION}

The occurrence of nuclear polyhedrosis viruses (NPVs) in marine shrimp of the genus Penaeus has been known for several years, having been first described in wild populations and later in cultured shrimp (Couch, 1974a, b, 1981, 1991, Brock \& Lightner 1990). The pathogenicity of the NPVs has been underlined by the high rate of larval mortalities encountered in hatcheries. The literature reporting these NPVs indicates the presence of 2 groups of viruses, classified according to the shape of the occlusion bodies (OBs), i.e. grossly rounded intranuclear OBs for the MBVtype (Monodon baculovirus) viruses, or tetrahedral OBs for the BP-type ('Baculovirus penaei') viruses.

•E-mail: bonami@crit.univ-montp2.fr
BP-type viruses, characterized only by the shape of the OBs, have been reported from 15 penaeid species belonging to 5 of the 6 subgenera of the genus Penaeus (Lightner 1993), and in the related penaeoids Trachypenaeus similis and Protrachypene precipua (Lightner unpubl. data). These BP-type NPVs are widely distributed in several separate regions of the Americas: Hawaii, the Eastern Pacific Coast, the Atlantic and Caribbean coasts of South and Central America and the Gulf of Mexico (Brock \& Lightner 1990). As evidenced by insect NPVs, there are many different species (or strains) of baculoviruses which occur in different host species and have similar OBs. Thus, it is not possible to distinguish them based only on the general shape of the OB. Analyses and characterization of their genomes are mandatory for their identification. Because of the range of subtle to highly significant morphometric differences amongst BP-type viruses from Hawaii, Gulf of Mexico, 
Western Atlantic and Eastern Pacific penaeids (Lightner et al. 1985, Brock et al. 1986, Lightner 1993), we assume that some will eventually be found to be different viruses. For this reason, and in keeping with the insect Baculovirus nomenclature as defined by the International Committee on Taxonomy of Viruses (ICTV), we suggest using the insect NPVs taxonomic rules for naming the crustacean baculoviruses (Francki et al. 1991). Because all of them have a singly enveloped nucleocapsid (S subtype), their generic name must be SNPV.

The first reported shrimp baculovirus was discovered in the pink shrimp Penaeus duorarum (Couch 1974a, b) and was named BP ('Baculovirus penaei') (Couch 1974b), = PdSNPV (Summers 1977). It is, to date, the most extensively researched crustacean baculovirus, and it was accepted by the ICTV as a member of the Baculoviridae family. It was accepted essentially on the basis of its morphological features (Couch 1974b) and on the demonstration that its genome was a large circular dsDNA molecule, about $75 \times 10^{6}$ Da (Summers 1977).

We report here the partial characterization of another BP-type strain, the PvSNPV from Penaeus vannamei, and the partial cloning of its genome.

\section{MATERIAL AND METHODS}

Virus strains. Based on morphological data obtained by electron microscopy on several BP-type isolates from different geographical regions (Lightner et al. 1985, Lightner 1993), we postulate that there are 4 different BP-type strains. Therefore, in this study we used 3 of the 4 strains and named them as follows: Gulf of Mexico (GM) strain, Hawaiian (H) strain and Pacific (P) strain. In addition, to distinguish between different isolates, the name of the location where isolation was done has been added.

In this work, we used baculovirus-infected white shrimp Penaeus vannamei for purification and cloning. The shrimp were collected in January 1991 from a commercial shrimp culture facility in Hawaii. The hepatopancreata, weighing approximately 0.8 to $2.0 \mathrm{~g}$ each, were excised from frozen specimens and forwarded by Dr James Brock (Aquaculture Development Program, Honolulu, HI, USA). The infection was confirmed in hepatopancreata by light microscopic visualization of the OBs. Although this virus was obtained from Hawaii, it was isolated from a population of $P$. vannamei that had originally been imported from Ecuador. Hence, this agent is considered to be the Pacific strain of PvSNPV (P strain/grown in Hawaii) to distinguish it from the Hawaiian strain which is known so far only in native $P$. marginatus (Lightner et al. 1985, Brock et al. 1986). The frozen hepatopancreata were stored for $6 \mathrm{mo}$ at $-70^{\circ} \mathrm{C}$ ) before being processed.
Virus isolation and purification. TN buffer (Tris $0.02 \mathrm{M}, \mathrm{NaCl} 0.4 \mathrm{M}, \mathrm{pH} 7.4$ ) was used during all steps of the following procedure and was used to prepare sucrose and $\mathrm{CsCl}$ gradients. Twenty hepatopancreata were homogenized in TN buffer using a Potter tissue blender A low speed centrifugation (10 min at $750 \times g)$ was used to pellet the OBs.

The purification of the OBs was achieved by first layering the resuspended pellet onto a 40 to $65 \%(\mathrm{~W} / \mathrm{W})$ sucrose gradient and centrifuging for $30 \mathrm{~min}$ at 112000 $\times g$ in a Sorvall AH629 rotor. The band containing the OBs was removed using a Pasteur pipette, diluted in TN buffer and pelleted for $45 \mathrm{~min}$ at $153000 \times \mathrm{g}$ in a Sorvall TH641 rotor. The purification of OBs was completed by layering the final suspension onto a 21 to $41 \% \mathrm{CsCl}$ gradient and centrifuging for $1 \mathrm{~h}$ at 286000 $\times g$ in a TH641 rotor. The gradient was extracted with a Büchler Autodensiflow and fractions of 20 drops were collected with an ISCO Retriever II. Optical density at $254 \mathrm{~nm}$ wavelength was recorded using an ISCO UA5 UV monitor.

Virions were isolated from the supernatant fluid of the first low speed clarification by pelleting for $30 \mathrm{~min}$ at $72000 \times g$ in an AH629 rotor. The resuspended pellet was layered onto a 30 to $50 \%$ sucrose gradient and centrifuged for $1 \mathrm{~h}$ at $112000 \times \mathrm{g}$. The gradient was extracted as described above, and the fractions containing virions were pelleted, after dilution, at 143000 $\times g$ for $35 \mathrm{~min}$ in a TH641 rotor. The purification was completed by layering the resuspended pellet onto a 21 to $41 \%$ (W/W) CsCl gradient which was centrifuged for $1.5 \mathrm{~h}$ at $153000 \times g$ in a TH641 rotor. The gradient was extracted and bands of interest were diluted and pelleted for $35 \mathrm{~min}$ at $153000 \times \mathrm{g}$ in a TH641 rotor. Pellets were resuspended in TN buffer before further analysis.

The buoyant density of the virions and the $O B$ subunits was separately determined by measurement of the refractive index of the respective 2 fractions collected after centrifugation in preformed 21 to $41 \%$ $\mathrm{CsCl}$ gradients in $\mathrm{TN}$ buffer for $14 \mathrm{~h}$ at $106000 \times g$ in the TH64 1 rotor.

Electron microscopy. The purification procedure was monitored by transmission electron microscopy (TEM) by examining the viral suspensions after they had been stained negatively with $2 \%$ sodium phosphotungstate (PTA) pH 7.0, using collodion-carbon coated grids in an Hitachi HU12 electron microscope operating at $75 \mathrm{Kv}$.

SDS-PAGE. For polypeptide separation, $12 \%$ SDSacrylamide vertical gel slabs (SDS-PAGE) were used according to a previously published protocol (Bonami et al. 1992). The run duration, the current, the molecular weight markers ( $\mathrm{Mr}$ ) and the stains used were similar to those given in a previous paper (Mari et al. 1993). 
Nucleic acid extraction. To extract the DNA from purified virions, we used the procedure described in a previous paper (Mari et al. 1993)

Agarose gel electrophoresis. Electrophoresis was performed in TBE buffer (Maniatis et al. 1982). Gels ranging from 0.7 to $1.2 \%$ agarose were used and stained with incorporated ethidium bromide $10.5 \mathrm{\mu g}$ $\mathrm{ml}^{-1}$ ). Phage Lambda HindIII, and HindIII-EcoRI DNA digests and phage $\Phi \times 174$ Haelll digests were used as $\mathrm{Mr}$ markers. Restriction enzymes (Boehringer, Mannheim) were used according to the manufacturer's directions

Partial cloning of the genome and library construction. The extracted viral DNA was digested with Bam HI. After electrophoresis in a $1 \%$ agarose gel, the separated DNA bands were recovered from the gel using the Geneclean II Kit (Bio 101) and were ligated using T4 DNA ligase (Boehringer) into the BamHI site of dephosphorylated pUC 18. Transformation was performed using competent Escherichia coli-DH5 $\alpha$ cells. Plasmid screening was done by agarose gel electrophoresis of recombinant DNA obtained from alkaline lysis minipreps of clones with and without prior digestion with restriction enzymes.

Gene probes. Five inserts, obtained from the genomic cloning of PvSNPV, were chosen and labeled for testing as gene probes. The 5 inserts were designated as B1.23, B3.9, B4.9, B8.4a, and B8.4b.

The Genius I Kit (Boehringer) was used according to the manufacturer's directions for labeling with digoxigenin (DIG), hybridization and detection.

To demonstrate the specificity of the constructed probes, in situ hybridizations were performed on paraffin sections of BP-infected and non-infected shrimps and on MBV (Lightner 1992) infected individuals

Southern transfer (Maniatis et al. 1982) and dot-blot techniques were performed on nitrocellulose membranes BA85 (Schleicher \& Schuell).

To avoid problems with non-specific binding when using whole tissue, inserts were separately labeled with ${ }^{32} \mathrm{P}$ using a Random Primed Labeling Kit (Boehringer). Dot-blot techniques using the radioactively labeled probes (Brown 1987) were performed on Gene Screen Plus (DuPont NEM).

Samples. Samples that were tested with the gene probes consisted of purified BP-type DNA from several preparations, purified BP-type OBs, semi-purified supernatant fluids containing BP-type nucleocapsids (diluted bands issued from the sucrose gradient) and infected and uninfected crude tissue homogenates of the hepatopancreas (HP). Additionally, purified preparations of other penaeid shrimp viruses were also tested. The other viruses tested were: infectious hypodermal and hematopoietic necrosis virus (IHHNV), hepatopancreatic parvo-like virus (HPV) and reo-like virus (REO-type III) (Lightner 1992).

\section{RESULTS}

\section{Virus purification}

The OBs obtained after the 40 to $65 \%$ sucrose gradient were located approximately $4 / 5$ of the way down the tube (near the bottom). Due to the fragility of the OBs, the majority of them had dissociated into $O B$ subunits (OBS = polyhedrin units) after CsCl gradient centrifugation, and they exhibited a buoyant density of $1.305 \mathrm{~g}$ $\mathrm{ml}^{-1}$. Some virions were found in a faint band located at a density of about 1.25 to $1.26 \mathrm{~g} \mathrm{ml}^{-1}$. In an identical type of $\mathrm{CsCl}$ gradient, the purified free virions formed a band of buoyant density equal to $1.265 \mathrm{~g} \mathrm{ml}^{-1}$.

\section{Ultrastructure}

After negative staining, the virions of the 'purified band' exhibited different stages of degradation and disruption. Their high sensitivity to PTA is presumably due to osmotic changes during the negative staining procedure

Intact enveloped particles, 312 to $320 \mathrm{~nm}$ in length and 75 to $87 \mathrm{~nm}$ in diameter, possessed appendages at both extremities, which are believed to be envelope extensions (Fig 1). Particularly after the sucrose gradient, some (but very few) were abnormally short or long, measuring as short as $250 \mathrm{~nm}$ and as long as $900 \mathrm{~nm}$ in length (Fig. 2).

Normal nucleocapsids (Fig. 3) were 306 to $312 \mathrm{~nm}$ in length and 62 to $68 \mathrm{~nm}$ in diameter. The end of the nucleocapsids was 'capped' with a trilaminar (not clearly visible on this picture) structure that was 16 to $18 \mathrm{~nm}$ thick. The nucleocapsids demonstrated a 'crosshatched' appearance composed of rows of surface structures spaced approximately $6 \mathrm{~nm}$ apart and suggesting an helical pattern, with an angle of about $50^{\circ}$ to the long axis of the nucleocapsid.

The OB subunits (OBS) were 17 to $19 \mathrm{~nm}$ in diameter (Fig. 4). They were penetrated to varying degrees by PTA, thus resembling 'full' and 'empty' icosahedral viral particles. These polyhedron subunits were grossly rounded in profile, while some appeared obviously 6-sided.

\section{SDS-PAGE of the polyhedrin}

In SDS-PAGE, using $12 \%$ acrylamide gels, the OBS were resolved as one major polypeptide with a molecular weight of $52 \mathrm{kDa}$ (Fig. 5). 


\section{Restriction pattern of the viral genome}

The extracted viral DNA was digested with the restriction endonuclease BamHI. This digested DNA and a small amount of the undigested DNA genome were subjected to electrophoresis in a $1 \%$ agarose gel. Undigested DNA migrated a distance corre- sponding to the first bands of the Mr markers, i.e. demonstrating a size greater than $23 \mathrm{kbp}$. Digested DNA was resolved in 7 faint bands (A to $G$, by convention with decreasing size), with estimated sizes: $\geq 23,11.7,8.2,4.8,4.0,2.9$ and $1.1 \mathrm{kbp}$. The first band (A) could contain 2 or 3 high Mr bands; moreover, because of the small amount of DNA available,
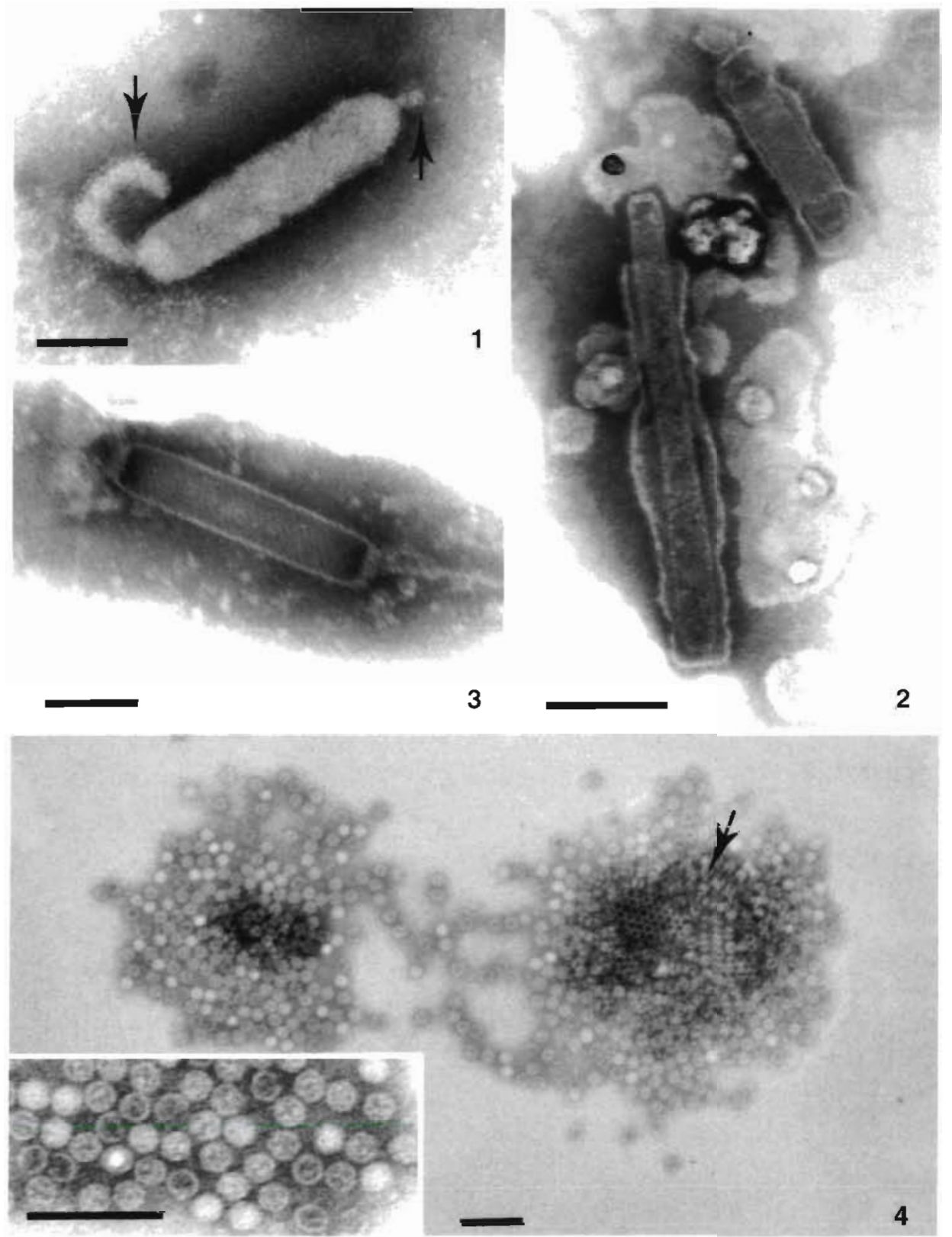

Figs. 1 to 4. PvSNPV from Penaeus vannamei. Fig. 1 Negative staining of a purified enveloped particle of PvSNPV. Envelope extensions are shown by arrows. Subunits and small projections are visible on the envelope surface. PTA. TEM. Bar $=100 \mathrm{~nm}$. Fig. 2. Two abnormal particles found in preparations after sucrose gradient fractionation. One particle is shorter than the normal virions, while the second particle is much longer and is also thinner in diameter. Remnants of the disrupted envelopes are present. PTA. TEM. Bar $=200 \mathrm{~nm}$. Fig. 3. Purified PvSNPV normal nucleocapsid. PTA. TEM. Bar $=100 \mathrm{~nm}$. Fig. 4. Purified PvSNPV polyhedra subunits (= OBS). They exhibit different degrees of PTA penetration, resembling 'full' and 'empty' virus-like particles; some appear 6-sided (inset). A part of the crystal (polyhedron) remains in the preparation (arrow). PTA. TEM. Bars $=100$ nm 


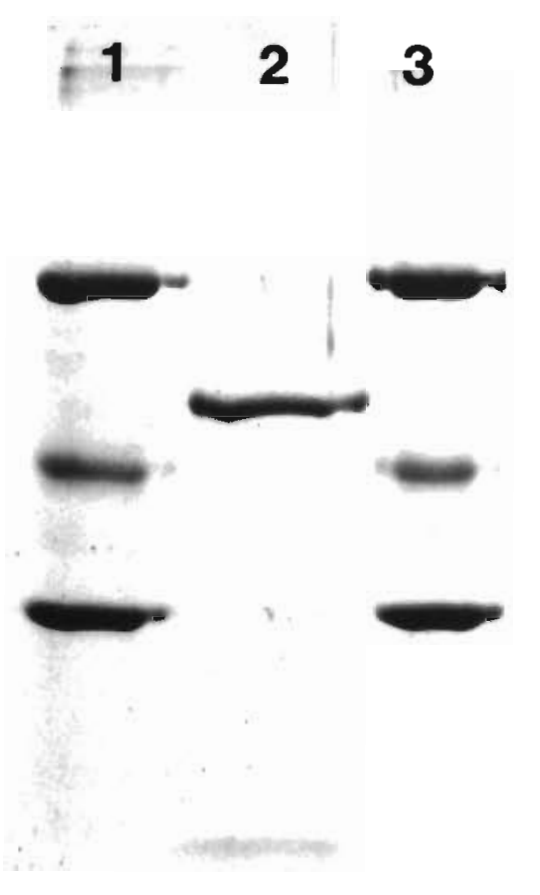

Fig. 5. SDS-PAGE of OBS in $12 \%$ acrylamide gel. Lanes 1 and 3: $\mathrm{Mr}$ markers (BSA: $66 \mathrm{kDa}$; egg albumin: $45 \mathrm{kDa}$; trypsinogen: $29 \mathrm{kDa}$ ); Lane 2: PvSNPV (P strain, grown in Hawaii) OBS

possible additional bands of lower $\mathrm{Mr}$ were not visible.

\section{Cloning of the BamHI digested genomic pieces}

Except for the A band which contained DNA fragments too large to be cloned in the pUC 18 vector, the DNA contained in the other bands ( $B$ to $G$ ) was recovered from the gel using the Geneclean II Kit and subsequently ligated into the BamHI site of the plasmid pUC 18. Four libraries were produced by combining the $\mathrm{B}$ and $\mathrm{C}$ bands together, the $\mathrm{D}$ and $\mathrm{E}$ bands together (because they were too close in the gel to be excised separately), and leaving the $F$ and $G$ bands separate.

An initial screening demonstrated numerous clones containing a recombinant plasmid with 2 BamHI sites and an insert of a similar size to the restriction fragments used for cloning. Some other clones were found which contained a recombinant plasmid with only 1 BamHI site. Overall, more than 300 recombinant plasmids containing inserts of interest were obtained.

\section{Characterization and mapping of the inserts}

Each group of inserts was characterized by the presence of the $2 \mathrm{BamHI}$ sites at the extremities, its size, its orientation in the plasmid and by the presence of restriction endonuclease sites (EcoRI and HindIII). After restriction mapping, cloned $\mathrm{C}$ and $\mathrm{E}$ bands were each found to possess 2 different but similarly sized fragments, giving a total of 8 different inserts named B to $I$, renaming the previous ones, B to $G$. By combination of single or double digestions with endonucleases, maps of selected inserts of each group were constructed (Fig. 6)

\section{Gene probes and hybridization assays}

A Southern transfer of the 5 inserts labeled as gene probes (C, D, E, F and I, named B8.4a, B8.4b, B4.9, B3.9 and $\mathrm{B} 1.23$, respectively) demonstrated no homology between the inserts. When the gene probes were used to test samples by dot-blot, a strong reaction was demonstrated to the unlabeled BP-type (PvSNPV/P strain grown in Hawaii) cloned DNA fragments (not shown) and (Fig. 7) the purified genomic DNA (row 2a) which were used as positive controls. Positive reactions were also demonstrated to preparations of BPtype DNA purified from Penaeus vannamei infected with a BP-type virus from Ecuador (PvSNPV/P strain grown in Ecuador), (row 2d, e). Likewise, a strong reaction was demonstrated to OBs purified from the original infected shrimp (PvSNPV/P strain grown in Hawaii) (not shown), while a moderately strong reaction was demonstrated to OBs purified from $P$. vannamei from Ecuador (PvSNPV/P strain) and OBs purified from $P$. aztecus from Mississippi (PaSNPV/GM strain grown in Mississippi) (row 2b). A positive reaction was also observed to PVSNPV/P strain infected HP tissue (result not shown), while no reaction was observed to uninfected HP tissue (row $1 \mathrm{a}$, b). No reaction was demonstrated to the shrimp viruses REO-III, HPV, and IHHNV, unrelated to the baculoviruses (row 1d, e, c, respectively).

Using an equimolar mixture of DIG-labeled inserts (B8.4a, B8.4b, B4.9, B3.9 and B1.23) as probes, we demonstrated by in situ hybridization the specificity of these probes; particularly the strong reaction of infected nucleoplasms known to contain large amounts of viral and proviral non-occluded material (published in a different study using the probes described here; Bruce et al. 1993). Sections of uninfected hepatopancreata did not react with the probes, nor did sections from MBV-type infected (PmSNPV) hepatopancreata.

\section{DISCUSSION AND CONCLUSION}

The TEM study of negatively stained viral and subviral particles after purification constitutes the first data 


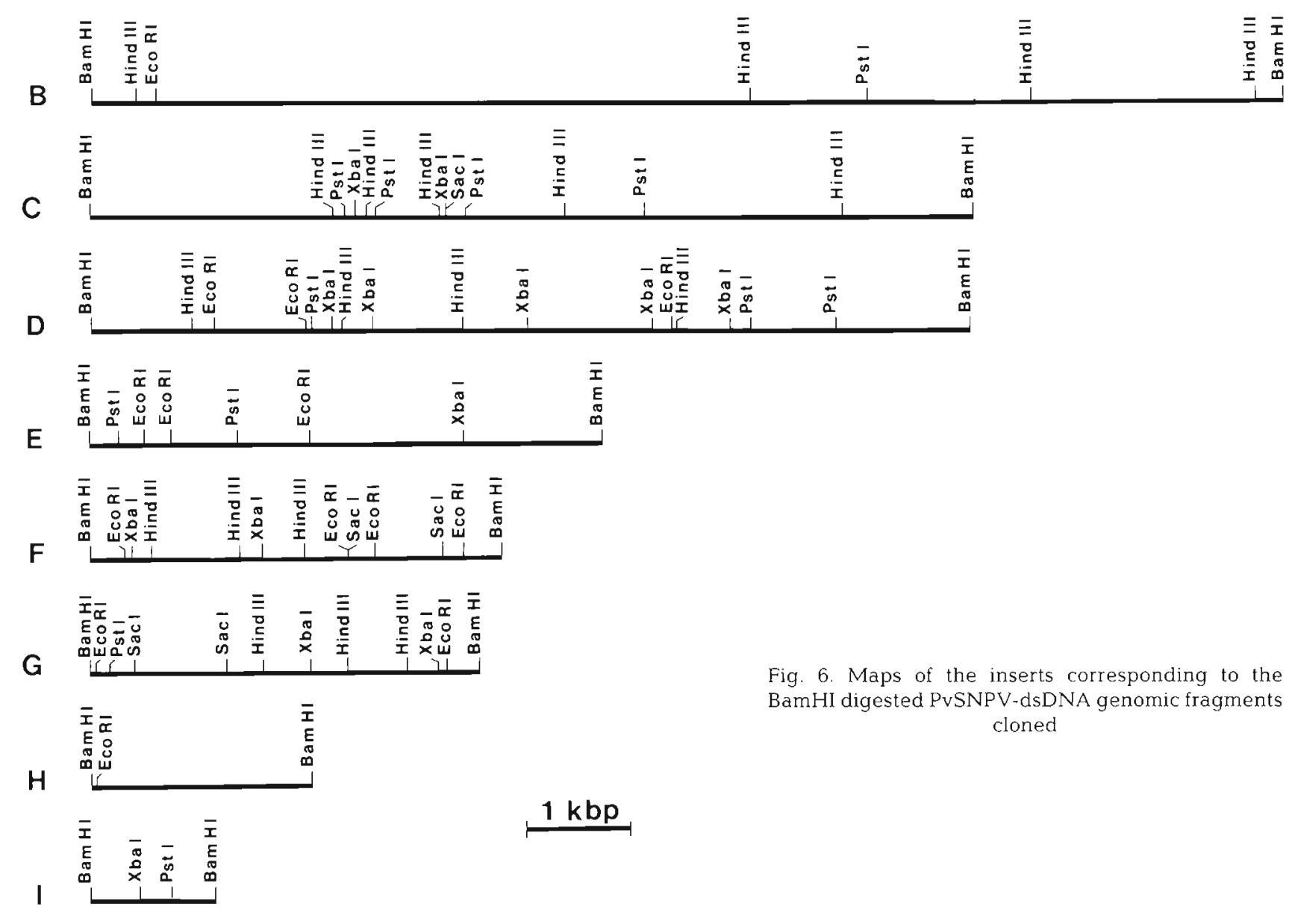

obtained for this type of pathogen (particularly the enveloped particles and the polyhedrin subunits) since its discovery (Couch 1974a). A picture of a negatively stained nucleocapsid without indications as to its acquisition was published earlier by Johnson \& Lightner (1988); our results confirm its general superficial structure and morphology. Sizes of negatively stained enveloped particles and nucleocapsids correspond approximately to the values determined in TEM sections by Couch (1974b), but differ from values reported for a BP-type virus (PmSNPV/H strain) from Penaeus marginatus (Brock et al. 1986). Compared with MBVtype virions (PmSNPV/MBV-type), the BP-type virions are larger in size, except for the diameter of the nucleocapsids, which is identical (Mari et al. 1993).

Like PmSNPV/MBV-type (Mari et al. 1993), PvSNPV/BP-type has rounded or 6-sided OB subunits that resemble full or empty 'viral particles' when negatively stained. The OB subunits of the 2 viruses differ only in their size and their Mr as determined by SDS-PAGE. In several different electrophoresis gels, the value obtained for the PVSNPV polyhedrin was a little larger $\begin{array}{llllll}a & b & c & d & e & f\end{array}$

1
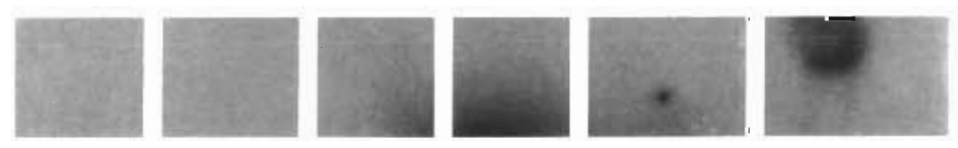

2
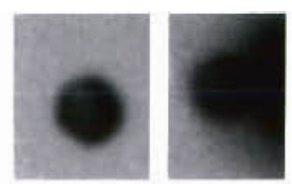

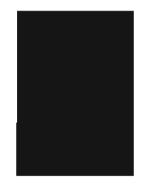

Fig. 7 Autoradiograph of dot blot probed with equivolume mix of $5^{32} \mathrm{P}$ random prime labeled PVSNPV DNA fragments. Row 1: (a and b) uninfected tissue, (c) IHHNV, (d) REO-III, (e) HPV, (f) OBs (PvSNPV/P strain, grown in Ecuador). Row 2: (a) DNA (PvSNPV/P strain, grown in Hawaii), (b) OBs (PaSNPV/GM strain, grown in Mississipi), (c) supernatant fluid (PvSNPV/P strain, grown in Hawaii), (d and e) DNA (PvSNPV/P strain grown in Ecuador) 
$(52 \mathrm{kDa})$ than the value $(50 \mathrm{kDa})$ determined by Summers (1977). This difference may be insignificant and may be due to variations in experimental conditions or it may indicate that different BP-type SNPVs infect these 2 shrimp species, the PvSNPV/P strain and the PdSNPV/GM strain, as has been previously suggested (Lightner et al. 1985). As was described for PmSNPV/ MBV-type (Mari et al. 1993), the virus described here possessed the characteristic appendages located at each extremity of the enveloped virion that resemble those which occur in some nonoccluded baculoviruses (Pappalardo et al. 1986, Hüger \& Krieg 1991). The PvSNPV nucleocapsid resembles those of the nonoccluded viruses [ $\tau$ (Tau) virus] from the marine crab Carcinus mediterraneus (Pappalardo et al. 1986, Hüger \& Krieg 1991) and the nonoccluded baculovirus from Oryctes rhinoceros (Monsarrat 1978) in having a suggestion of a helical superficial structure of the capsid.

The electrophoretic pattern obtained after digestion of the PvSNPV (P strain grown in Hawaii) viral genome with the restriction endonuclease BamHI constitutes the first data on the structure of the genome. Screening of the cloned DNA pieces revealed a total of at least 9 BamHI-digested DNA fragments (A to I) with a size of 21 to $23 \mathrm{kbp}, 11.4,8.4,8.4,4.9,3.9,3.7,2.1,1.2 \mathrm{kbp}$. The 8 cloned fragments ( $\mathrm{B}$ to I) represent a total of $44 \mathrm{kbp}$ of the entire genome. This is approximately $40 \%$ of the estimated size of the genome $\left(75 \times 10^{6} \mathrm{Da}=\right.$ $114 \mathrm{kbp}$ ) obtained by length measurement of isolated circular dsDNA genome (Summers 1977), assuming that PvSNPV and PdSNPV have the same genomic size. This value indicates that the first band ( $>23 \mathrm{kbp}$ ) obtained from the gel electrophoresis probably contains multiple large fragments.

The lack of homology between the inserts selected to be labeled as probes indicates that the inserts are from different regions of the genome. The results obtained when the inserts were labeled as probes indicated that the gene probes are specific for BP-type viruses, since they reacted to purified BP-type viral DNA and semipurified (i.e. supernatant) preparations containing BPtype nucleocapsids. The results also show that they do not react with the other shrimp viruses HPV, IHHNV, and REO-III, the MBV (another shrimp baculovirus) and do not cross-react with uninfected shrimp tissue.

The in situ hybridization results confirm the specificity of the probes for the virus as indicated by the strong colored reactions obtained in infected nucleoplasm (where the viral nucleic acid is abundant due to viral replication), and no reaction with healthy tissues.

These results, particularly the acquisition of cloned genomic fragments able to be used as genomic probes, constitute an essential step towards new investigations on this shrimp viral disease, e.g. study of the different viral strains, investigations on viral transmission in farmed shrimp (particularly the possible vertical transmission from infected adults to larvae, which appears to be a significant obstacle to controlling the disease in hatcheries), and attempts to detect a nonpathogenic strain to be used as a vector (as is already being done with insect baculoviruses)

Acknowledgments. This work was funded in part by Sea Grant, U.S. Dept of Commerce, and by grant \# 88-38808-3320 from the U.S. Dept of Agriculture, C.S.R.S. to the Marine Shrimp Farming Consortium. It was also funded by the French Centre National de la Recherche Scientifique.

\section{LITERATURE CITED}

Bonami JR, Lightner DV, Redman RM, Poulos B (1992) Partial characterization of a virus (LOVV) associated with histopathological changes of the lymphoid organ of penaeid shrimps. Dis aquat Org 14:145-152

Brock JA, Lightner DV (1990) Diseases of Crustacea 3.1 Diseases caused by microorganisms. In: Kinne $O$ (ed) Diseases of marine animals. Biologische Anstalt Helgoland, Hamburg, 245-349

Brock JA, Nakagawa LK, Van Campen H, Hayashi T, Teruta $S$ (1986) A record of Baculovirus penaei from Penaeus marginatus Randall in Hawaii. J Fish Dis 9:353-355

Brown T (1987) Hybridization analysis of DNA blots. Hybridization analysis of a DNA blot with a radiolabeled DNA probe In: Asubel FM et al. (eds) Current protocols in molecular biology. Greene Publ Assoc and Wiley-Interscience, New York, p 2.10.1-2.10.3

Bruce LD, Redman RM, Lightner DV, Bonami JR (1993) Application of gene probes to detect Baculovirus penaei in fixed tissue using in situ hybridization. Dis aquat Org 17. 215-221

Couch JA (1974a) Free and occluded virus, similar to Baculovirus, in hepatopancreas of pink shrimp. Nature 247:229-231

Couch JA (1974b) An enzootic nuclear polyhedrosis virus of pink shrimp: ultrastructure, prevalence, and enhancement. J Invertebr Pathol 24:311-331

Couch JA (1981) Viral diseases of invertebrates other than insects. In: Davidson EW (ed) Pathogenesis of invertebrate microbial diseases, Chap 5. Allanheld, Osmun Publ, Totowa, NJ, p $127-160$

Couch JA (1991) Baculoviridae. Nuclear polyhedrosis viruses. Part 2. Nuclear polyhedrosis viruses of invertebrates other than insects. In: Adams JR, Bonami JR (eds) Atlas of invertebrate viruses, Chap 6. CRC Press, Boca Raton, p $205-226$

Francki RIB, Fauquet CM, Knudson DLK, Brown F (1991) Classification and nomenclature of viruses. Arch Virol Suppl 2:1-450

Hüger AM, Krieg A (1991) Baculoviridae. Nonoccluded baculoviruses. In: Adams JR, Bonami JR (eds) Atlas of invertebrate viruses, Chap 9. CRC Press, Boca Raton, p $287-319$

Johnson PT, Lightner DV (1988) Rod-shaped nuclear viruses of crustaceans: gut infecting species. Dis aquat Org 5: $123-141$

Lightner DV (1992) Shrimp virus diseases: diagnosis, distribution, and management. In: Wyban J (ed) Proceedings of the Special Session on Shrimp Farming. World Aquacul- 
ture Society, Baton Rouge, p 238-253

Lightner DV (1993) Diseases of penaeid shrimp. In: McVey JP (ed) CRC handbook of mariculture: crustacean aquaculture, 2nd edn. CRC Press, Boca Raton, p 393-486

Lightner DV, Redman RM, Williams RR, Mohney LL, Clerx

JPM, Bell TA, Brock JA (1985) Recent advances in Penaeid virus disease investigations. J world Maricult Soc 16:267-274

Maniatis T, Fritsch EF, Sambrook J (1982) Molecular cloning A laboratory manual. Cold Spring Harbor Laboratory, Cold Spring Harbor, NY

Mari J, Bonami JR, Poulos B, Lightner DV (1993) Preliminary

Responsible Subject Editor: J. E. Stewart, Dartmouth, Nova Scotia, Canada characterization and partial cloning of the genome of a baculovirus from Penaeus monodon (PmSNPV $=\mathrm{MBV}$ ). Dis aquat Org 16:207 -215

Monsarrat P (1978) Contribution à l'étude du virus d'Oryctes rhinoceros L. et de son impact écologique Thèse Doct Etat, Univ Sci Tech Languedoc, Montpellier II

Pappalardo R, Mari J, Bonami JR (1986) $\tau$ (Tau) virus infection of Carcinus mediterraneus: histology, cytopathology and experimental transmission of the disease. $\mathrm{J}$ Invertebr Pathol 47:361-368

Summers MD (1977) Characterization of shrimp baculovirus. Ecological Research Series, EPA-600/3-77-130, 35p

Manuscript first received: July 25, 1994

Revised version accepted: February 13, 1995 